\title{
The Unique Role of Realistic Reproduction in Sports Poster Design
}

\author{
Shanshan Zhao \\ Northeast Normal University \\ Changchun, China
}

\begin{abstract}
By studying the application and unique role of realistic representations in sports poster design, the cultural value and social influence of sports posters are fully exerted, especially in the prosperity and development of socialist culture with Chinese characteristics, and thus the promotion of Chinese sports culture. In the process of competitiveness, it has profound historical significance. In the contemporary social situation, compared with tangible sports activities, the intangible cultural connotation conveyed by sports poster design has broad social value.
\end{abstract}

Keywords—sports poster; realistic reproduction; culture

\section{INTRODUCTION}

Playbill is also called a poster, and the English language is "Poster". In the past when information communication is not fully technological, it is a powerful medium for people to quickly get news in their lives. With the development of visual culture, society has entered an era of unprecedented mass culture. Sports posters are part of modern poster design and are the way of publicity of sports activities. It expresses the form of posters based on sports content or learning from sports elements, and invokes all forms of artistic expression in order to allow accurate content transmission of the contents of the poster. Compared with other posters, sports posters have a wide range of communication and strong appeal. The reason is that sports posters are generally based on large-scale sports events, the competitive spirit of various sports events and the wonderful viewing, which have gathered powerfully in the world. The attention is added to the exposure and propaganda breadth of sports posters. Rudolf Arnheim mentioned that "the poster of art form, the most essential value of which is information transmission" in "Art and Visual Perception". [1] The realistic style of works in sports posters is the closest. Real images create a real kind of motion scene. From the perspective of information accuracy, many designs use the representation of realistic reproduction. Realistic reproduction is not only a real performance restoration, but also a simple natural imitation. The redefined, creative approach with a certain personal feeling, the use of this form in the design of sports posters, the perfect combination of sports and art, this form of expression is popular with the public, in large-scale sports events, sports culture. It is widely used in activities and commercial posters.

\section{The ApplicAtion OF SPORTS POSTER DESIGN REALISTIC RENDERING}

\section{A. Reproduce the Beauty of the Human Body and the Dynamic Beauty with Realism}

The form of realistic reproduction in sports events is first reflected in the real portrayal of the figure in the picture. In the poster design, the hand-painted style poster in the early 20th century became the mainstream of visual communication at that time. At this time, the illustration was officially applied to the Olympics. The posters show the athlete's physical beauty and dynamic beauty in the illustration, which became an early style. This humanistic realistic technique originated from the ancient Greek realistic human sculpture art. In the eyes of the ancient Greeks, the human body is beautiful. It is worthy of display and appreciation. Hegel mentioned in "Aesthetics" that the ancient Greeks regarded "the image of the person as the most free and beautiful image of all other images to appreciate" [2]. When ancient Greeks were engaged in sports, men often participated naked, which was seen as an important opportunity to show the beauty of form. Among them, in the "1912 Stockholm Olympic Games poster" (as shown in "fig. 1 "), the designer was inspired by the tradition of ancient Greek body art and nude competition. The naked athletes waved the flags of the participating countries; the poster of the 7th Olympic Games in Antwerp in 1920 also had the same the "retro" style, (as shown in "fig.2") the semi-nude discus thrower with rich ancient Greek characteristics is very similar to the work of the ancient Greek sculpture artist Milon. "The Discus thrower", (as shown in "fig.3") which is recognized as a symbol of sports and bodybuilding, and it subtly and accurately represents the athlete's posture in sports. The pursuit of human beauty in sports posters is also a kind of "degenerate" effect on social aesthetic tendency. 


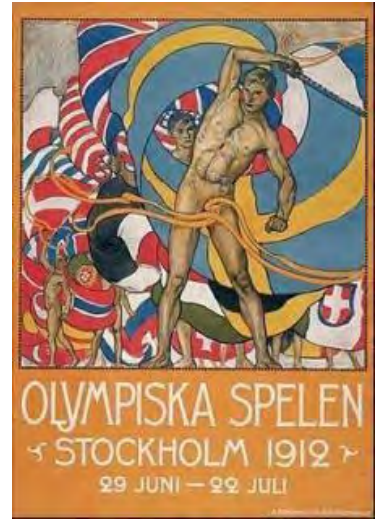

Fig. 1. Stockholm Olympics poster.

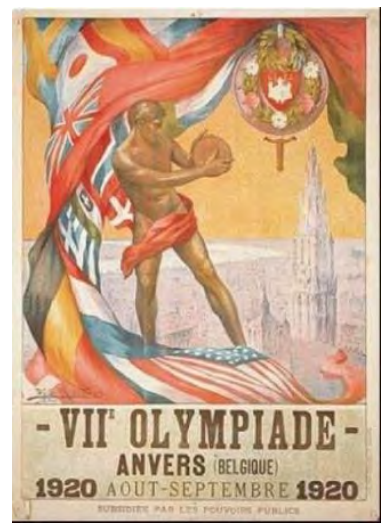

Fig. 2. Antwerp Olympics posters.

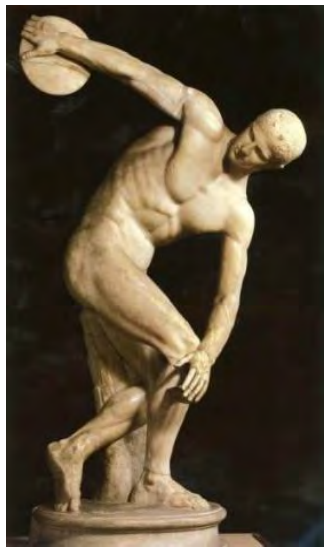

Fig. 3. Milon "The Discus thrower".

The realistic reproduction of sports posters is inseparable from the depiction of sports styles. The human body in sports can show bodybuilding and strength. At the same time, the dynamic has a strong visual impact, which not only highlights the tension of the sport, it can be said that it is the most favorable performance content of sports posters. Although they are of different forms, but the main theme is the same, the eternal beauty of this moment is also the biggest feature of sports posters. Because posters can only express an instant movement during exercise, this requires that when characterizing the subject of motion, the posture that best highlights tension and tension is selected, and it is necessary to study and correctly grasp the movement dynamics. In the early sports propaganda paintings in China, the realistic sports image is widely used. The propaganda paintings of the National Games show the fixed movements of the athletes throwing the javelin, and grasp the angle and arm of the body of the body before the full throw, as shown in "Fig. 4" The moment when the amplitude of the swing is in its maximum, the explosive force is exhibited. In the way of expressing dynamic beauty, photography technology has excellent expressiveness for the continuous capture of movements. The sports posters of the 2008 Beijing Olympic Games sports poster "Vibrant Beijing Beyond Dreams" Olympic Games are mainly composed of dynamic basketball players, as shown in "Fig. 5" The moment of leaping is coming out, and then the five-color line of five-ring color is used to make the picture rich in Chinese linear rhythm and interest. Let the posters be passionate and dynamic, fully reflecting that the Olympics are higher, faster and stronger.

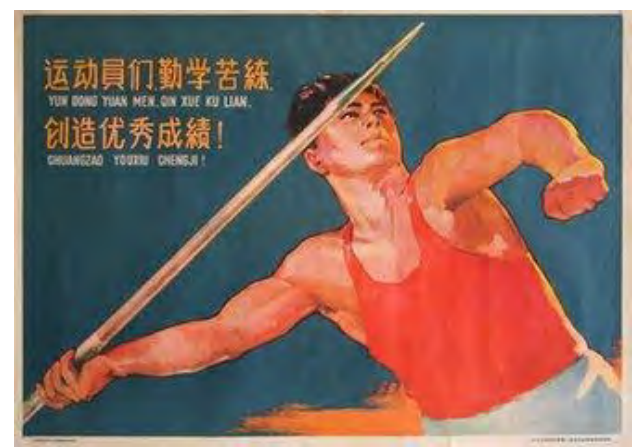

Fig. 4. National Games Poster.

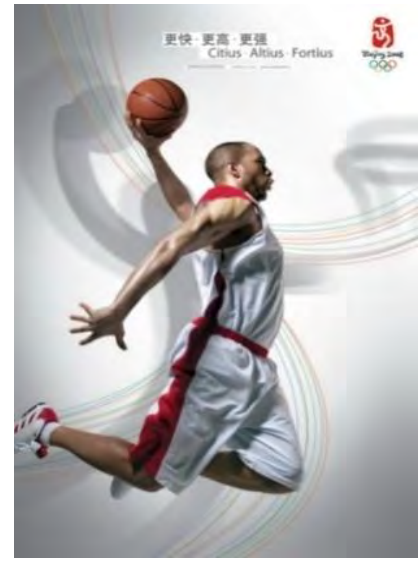

Fig. 5. "Vibrant Beijing Beyond the Dream" Beijing Olympic Games Sports Posters.

\section{B. Use Design to Sublimate Images}

With the development of technology, photography is involved in the design, as a design element, the form of realistic reproduction can be more resorted to by means of photography. Photography is not only about taking photos, but with personal thoughts and deep meanings, which can show the subject matter. However, the use of photography as 
a selection of posters can directly convey information, but if it is not handled well, it will become a simple illustration or a picture, which makes people feel a lack of design. To be acceptable to the audience, it also relies on the perfect appearance of the visual effects of poster design. Designing to sublimate images and give meaning to images is widely used in sports posters. For example, in the poster of the 1998 Nagano Winter Olympics in Japan, as shown in "Fig. 6", it changed the character-based form, and used the distant peaks and the close-know to rest on the snow. This scene blends the harmony between nature and sports. Many photo-style posters have truly restored the scene, but the reorganization of the design gives it a new meaning. Among them, the 1986 Mexico World Cup poster, as shown in "Fig. 7" is representative. Mexico is an important birthplace of ancient civilizations in the Americas. The background of the poster is Mexico's iconic samurai stone pillar representing the Mayan culture. There is also a ball-like ornamental sport similar to football in the Mayan civilization. It also reflects the origin of Mexico and football and the long-standing civilization of Mexico. Football and humanoid projections, corresponding to each other, convey the culture of football and Mexico.

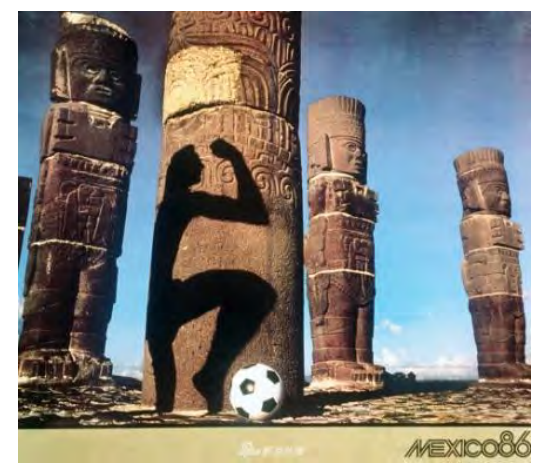

Fig. 6. Japan Nagano Winter Olympics Poster.

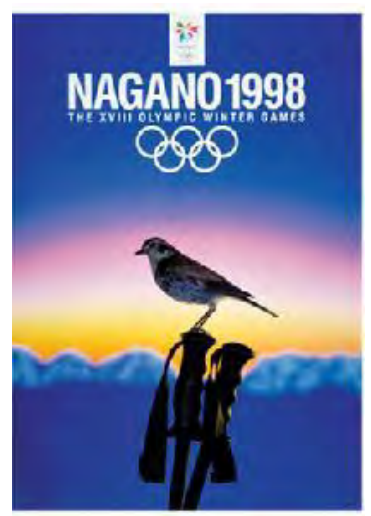

Fig. 7. Mexico World Cup Poster in 1986.

\section{Focus on Practicality and Business Value}

With the development of business and consumer demand, the promotion and promotion functions of posters have received increasing attention. Commercial posters are the most widely used in realistic sports posters. The streets and alleys of the city are full of advertising posters for various sports products. The task of commercial posters is to convey information, combined with business activities, to promote the company's operations and brands. The form of realistic reproduction is simple and direct, and can stimulate consumption intuitively. The content of commercial posters is centered on products. Therefore, in poster design, information is mainly transmitted by images, supplemented by brief text descriptions or concise and tempting slogans. This allows advertising posters to cover different cultures, different social groups, consumers of different educational levels, and easily understand the main content of the screen. And this is easy to attract people's attention to the poster, to maximize the promotion of the poster. Nike's famous slogan "JUST DO IT" is well known. The various Nike products that match this slogan promote the self-awareness of young people and emphasize the movement itself. (as shown in "Fig. 8") Among the factors affecting consumer motivation, external environmental factors, such as culture, population environment, social status, reference groups, families, etc., of which culture is the most extensive and outermost. The cultural values of posters directly affect consumer behavior, and Nike's slogan is free and easy for young consumers. Poster design is also a clear theme, reducing unnecessary elements in the picture. Expressing clarity in the relationship between supply and demand, it also makes people more aware of what is needed, what is not needed, and the cultural values of young people.

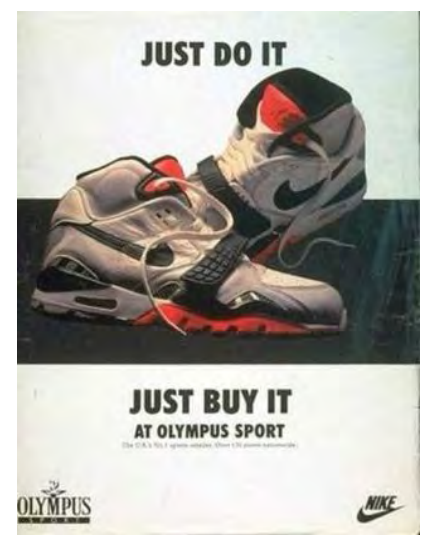

Fig. 8. Nike advertising poster.

\section{THE UNIQUE ROLE OF REALISTIC REPRODUCTION IN SPORTS POSTERS}

\section{A. The Accurate Information Transmission}

Realistic reproduction is a common form of expression, and intuitive and true restoration of things is its greatest advantage. Sports posters are purposeful information dissemination activities that are easy to understand for sports fans all over the world. In large-scale sports events, it is necessary for viewers around the world to accept information at a glance. Anyone who lives in any area with newspapers, magazines, television, or the Internet, as long as he pays attention to the content of the poster, he will have his own understanding of the content of the poster information. In 
order to form a consensus and eliminate the difference in understanding, it is necessary to intuitively and accurately express the content of the poster.

Realistic reproduction is the expression of content in an intuitive way. Image analysis believes that the interpretation of art works by image science is divided into three levels, which are the process of the table and the inside. First of all, it is a simple description stage of the pre-image, and the way of real-life reproduction is the first level of image analysis. In the direct observation of the human eye, the audience can obtain more accurate information, and then in the second level of image analysis stage, the composition of the source of the creative work is analyzed, and the composition and structure of the poster are analyzed. At the third level, it is the interpretation stage of imageology, and also the deep image analysis. The audience gradually understands the deep cultural connotation of posters. Compared with other forms of abstract freehand, the realistic reproduction method is easy to communicate, understand, and obtain accurate and fast information. Even for viewers of different cultural levels, as long as he can understand the Olympic rings and olive branches, he can get Olympic information.

\section{B. Reflecting the Value of Social Education}

Posters have an important impact in life. It is a very popular means of publicity. The poster design can reflect the cultural life of a region, the level of spiritual civilization, and the aesthetic level of the city as a whole. Poster design has a guiding role in people's spiritual and cultural life. Therefore, posters must assume the task of social atmosphere and social education. China's sports culture is an integral part of social culture, and sports activities are an aspect of social activities. The rapid development of sports has also accelerated the exchange and integration of civilizations. All kinds of largescale sports activities posters are the most direct social and cultural carriers, with strong information content and communication capabilities. The social spiritual civilization that transmits positive energy is the social responsibility of sports posters.

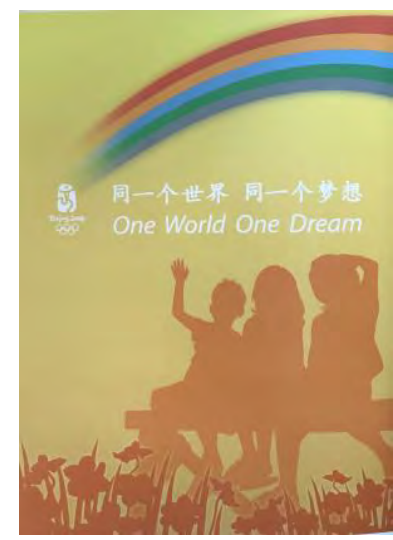

Fig. 9. Olympics poster (middle school student version)

Among them, the Beijing Olympic Poster Middle School Edition, as shown in "Fig. 9" is aimed at the influence of sports culture on young people. The poster design is in the form of a silhouette, three intimate partners sitting together, looking up at the sky, with a rainbow across the head. The design is generally warm in yellow, with bright colors that are in keeping with the psychology of children and teenagers. This poster also symbolizes the youthful vitality of the youth. The rainbow sets up a bridge of friendship between young people from all over the world. It perfectly interprets "the same world, the same dream." The concept of sports poster communication is used to touch the inner depths of the audience, and it is sublimated into a value concept in the consciousness of young people, which turns into a concept of life, values, and transformation into lifelong behavior. The educational significance of the Olympic Movement is not only the meaning of physical education, but more importantly, it emphasizes the perfect personality of shaping a person through sports. Promoting the harmonious development of mind and body is the foundation of education. In education, family education, school education, and social education constitute three aspects of one-person education. The first two have specific educational places and educators, while social education is different, with a wide range and different forms. One of the ways is social activity. Let sports be posted in social activities, admire a correct value, outlook on life and realize social education responsibility.

\section{Reflecting the Influence of Sports Culture}

The vigorous development of sports has promoted the development of sports, and at the same time created a stage for sports artists. Sports posters have become a window for countries to show their own country, their own culture and art. Culture is a manifestation of a nation and a country's spiritual civilization. The British anthropologist R. Foss said, "Culture is society. What is society and what culture is." The design of sports events is inclusive and regionally inclusive. The country promotes national culture with the charm of sports posters. It makes the regional national characteristics have an international appearance, allowing sports posters to spread widely in the world. Every art style occurs from a fixed cultural background. A fixed cultural background refers to a consistent national culture, a way of thinking, a language, and an artistic expression symbol in the region. These factors have become the driving force for national development.

Sports posters can enter various fields across national, ethnic, class and language barriers, and communicate and communicate with people around the world. It contains many symbols of human evolution and development, which can be considered as the future world language. The use of graphic language in sports posters is an important way to achieve the combination of sports posters and sports culture. In the design process, according to the theme of the event, the content of the sport and the needs of the market, the sports poster integrates elements such as graphics, text and color into one and is realized by computer-related design software. With the combination of sports poster design and sports culture, the focus of sports poster design tends to be the expression of sports culture that integrates character shaping, plot development, expression techniques and spiritual life. Culture has become the main essence of sports posters. The 
combination of sports culture and sports poster design can not only improve the cultural value of sports posters, enhance the appeal of sports posters, but also enhance the appeal of sports posters and achieve the purpose of information publicity.

\section{Improve the Aesthetic Value of Sports Posters}

The use of graphic language in the design of sports posters not only enhances the visual impact of posters, but also enhances their aesthetic value. Sports posters are the spread of sportsmanship and play an important role in raising awareness of sports events, transmitting information, attracting audience attention, and stimulating ticket sales revenue. Aesthetic value is an objective and natural nature with real phenomena. It does not depend on human subjective consciousness, but it forms a relationship with people and society in the process of social history practice. Therefore, the aesthetic value of sports posters reflects the most essential part of the sports, namely the spiritual essence of sports and the shock and moving of people's emotional life. These complex connections and factors are intertwined to form the basis of the aesthetic value of sports posters. The use of graphic language in the design of sports posters not only plays an important role in the spiritual and value performance of sports, but also plays an important role in reducing the aesthetic evaluation of the audience and improving the aesthetic value of the poster itself.

During the 2008 Beijing Olympic Games, the "Art of the World - The 100-year Olympic Poster Exhibition" was jointly organized by Victoria and the Albert Museum and the Capital Museum. The content of the poster exhibition is a collection of Olympic posters by the Victoria and Albert Museum, in the order of the history of the Olympic Games. Since the birth of the first modern Olympic Games in 1896, there have been a large number of Olympic posters, many of which are representations of realistic reproduction, extending from early illustration art to modern posters. Although these Olympic posters have been withdrawn from the Olympic Games and completed the task of transmitting information, they have important cultural and artistic values. We can see the changes in artistic styles in various historical periods from the posters, and we can also deeply appreciate the aesthetic value of realistic reproduction forms in sports posters and become the finest of sports visual culture.

\section{CONCLUSION}

The realistic reproduction of the design of sports posters is the most intuitive and easy to communicate expression method, which can keep the scattered and short-lived beauty in sports in art design. Studies have shown that the dissemination of sports posters has a direct impact on whether or not its art form is understood and accepted by the public. The means of expression used in realistic reproduction depends on whether it is consistent with the development of the times and society, and whether it is consistent with the sports culture it carries. Only by constantly seeking the integration of sports and art and social culture is the innovation point that sports poster art really needs to explore.

\section{REFERENCES}

[1] Rudolf Arnheim. Art and Visual Perception [M] Teng Shouyi Translated, Chengdu Sichuan People's Publishing House, 1998.142.

[2] Hegel Aesthetics: Volume III Beijing: The Commercial Press 1996. 